\title{
Análisis dinámico de trayectorias laborales a través del concepto de flexiguridad
}

\author{
Ángel Alonso Domínguez \\ Universidad de Oviedo \\ alonsodangel@uniovi.es
}

Recibido: 15-07-2014

Aceptado: 05-06-2015

\section{Resumen}

El artículo realiza un análisis dinámico para conocer si el mercado laboral español responde a las características de los mercados de trabajo transicionales, desde un enfoque de flexiguridad. A través de la Muestra Continua de Vidas Laborales se estudian las trayectorias de los trabajadores españoles durante el período 2007-2010, que abarca el final de la expansión de la economía española y el comienzo de la actual crisis de empleo. De la conjunción del tema elegido, el enfoque y la base de datos utilizada, resulta una perspectiva novedosa en nuestro país. Se ofrece evidencia empírica de la evolución de los episodios de empleo y paro, del grado de rotación del mercado laboral español y de las dificultades de determinados colectivos para realizar transiciones en y hacia el empleo. Los resultados muestran un mercado de trabajo en el que a) las transiciones se encuentran bloqueadas, y b) existe una alta inseguridad laboral.

Palabras clave: flexiguridad; transiciones laborales; empleo; muestra continua de vidas laborales; mercados de trabajo transicionales. 


\title{
Dynamic Analysis of Employment Trajectories through the Concept of Flexicurity
}

\begin{abstract}
The paper presents a dynamic study of the Spanish labour market which tries to determine if it matches the characteristics of transitional labour markets from a flexicurity approach. Employment trajectories of Spanish workers during the years 2007-2010 are studied using the Continuous Sample of Working Lives. This period covers the end of the expansion of the Spanish economy and the beginning of the current employment crisis. From the combination of the chosen topic, the approach, and the database used, this is a novel perspective in our country. The article shows evidence of the evolution of the employment and unemployment spells, the Spanish labour market turnover degree, and the difficulties of some groups for carrying out transition between employment and unemployment. The results obtained show a labour market in which a) transitions have come to a halt, and b) there is high job insecurity.

Keywords: Flexicurity; Transitional Labour Market; Employment; Continuous Sample of Working Lives.

\section{Referencia normalizada}

Alonso Domínguez, A. (2015): “Análisis dinámico de trayectorias laborales a través del concepto de flexiguridad", Política y Sociedad, 52 (3), pp. 819-844.

Sumario: 1. Introducción. 2. Los mercados de trabajo transicionales: seguridad versus flexibilidad. 3. Flexiguridad del mercado de trabajo español: perspectiva comparada. 4. Metodología del estudio empírico. 5. Resultados: análisis de transiciones. 6. Conclusiones

7. Bibliografía.
\end{abstract}




\section{Introducción}

La búsqueda del equilibrio entre flexibilidad y seguridad (flexiguridad) en el mercado de trabajo no es una aspiración nueva. Desde la finalización de la Segunda Guerra Mundial y durante todo el período de la Guerra Fría se han alentado medidas tendentes a alcanzar la armonía entre protección social y flexibilización del mercado de trabajo, si bien no es hasta finales del siglo XX cuando el debate se actualice, sobre todo cuando el Estado de Bienestar comienza a ser cuestionado. En los años ochenta, la hegemonía de las políticas neoliberales de Reagan y Thatcher, proclives a los procesos de individualización de las relaciones laborales (Serrano et al., 2009) y con su mirada puesta exclusivamente en el mercado, provoca que las principales medidas de reformas se centren en las mejoras productivas soslayando la función protectora (Burroni y Keune, 2011), dentro de un marco general en el que se ponen de manifiesto nuevos problemas asociados a la globalización económica. Algunas de estas dificultades se reflejan rápidamente en el ámbito laboral, provocando la toma de conciencia de la necesidad de una nueva ponderación entre flexibilidad y seguridad.

No existe una definición universalmente aceptada sobre flexiguridad. El presente artículo utiliza el significado más restrictivo utilizado por la Comisión Europea que la define como "una estrategia integrada para potenciar, a un tiempo, la flexibilidad y la seguridad en el mercado laboral" (Comisión de las Comunidades Europeas, 2007). Con la flexiguridad como punta de lanza de sus políticas laborales, la Unión Europea (UE) está apostando por una nueva estrategia de empleo que favorezca la competitividad y la adaptación a un nuevo contexto económico y laboral caracterizado por un alto nivel de incertidumbre y la dificultad para asegurar la estabilidad en el puesto de trabajo (Unión Europea, 2007). Flexibilidad, seguridad, empleabilidad, activación y transiciones son conceptos muy presentes en las iniciativas comunitarias que la UE pretende impulsar a través de la Estrategia Europa 2020 y a partir de los modelos de referencia — Dinamarca, Holanda o Austria-.

El artículo trata de aportar evidencia empírica sobre la flexibilidad y la seguridad del mercado de trabajo en España, y para ello el análisis se centra en el período 2007-2010, una etapa que abarca unos años en los que se constatan ya los efectos que ha tenido la crisis económica sobre el empleo. Esta etapa abarca unos años en los que se constatan ya los efectos que ha tenido la crisis económica sobre el empleo, y es precisamente en estos ciclos de recesión económica en donde la flexiguridad resulta de más utilidad.

El estudio está organizado como sigue. Primero, se presenta el concepto analítico de Mercados de Trabajo Transicionales, a partir de una discusión más amplia sobre la flexiguridad y el Modelo Social Europeo, que servirá de marco teórico al artículo. Segundo, se aborda la aproximación metodológica, en la que se relacionan los indicadores claves con la hipótesis de partida. Tercero, se aborda la flexiguridad del mercado laboral español en perspectiva comparada. Cuarto, se presentan los resultados del análisis realizado con la Muestra Continua de Vidas Laborales (MCVL) como fuente de datos. Y quinto, se presentan las conclusiones basadas en los resultados obtenidos. 


\section{Los mercados de trabajo transicionales: seguridad versus flexibilidad}

Desde mediados de los años 90, cuando el neologismo "flexicurity" es adoptado por la UE, la flexiguridad comienza a ser incluida en la agenda política de los principales países europeos. El Consejo y la Comisión Europea han sido los dos pilares fundamentales del proceso, al que han dotado de los impulsos necesarios para su desarrollo, definiendo las orientaciones políticas generales que han aplicado después los diferentes socios comunitarios. La intención es convertir a la UE en la primera y más competitiva economía del mundo, capaz de armonizar un mercado laboral que registre más y mejores empleos, al tiempo que se avance también en una mayor cohesión social (European Communities, 2001).

En su etapa inicial, la flexiguridad buscaba respuestas a los retos impuestos por la globalización para alcanzar el equilibrio entre la flexibilización del mercado y los desarrollos sociales. Este sentido original de la flexiguridad, mostraba una cara "más humana" y más ajustada al Modelo Social Europeo (MSE) que a la simple desregulación (2007: 7). Es ésta una concepción más cercana a la que ofrecen los Mercados de Trabajo Transicionales (MTT). Los MTT plantean una respuesta institucional adaptada a las dificultades e incertidumbres que se ciernen sobre los trabajadores actuales, basada en "transiciones integradoras, creíbles y accesibles" (De Gier y Van den Berg, 2006: 394-395). Es la "reinstitucionalización flexible de los mercados de trabajo", según la terminología de Köhler y Martín-Artiles (2005), que permite responder a los episodios básicos del ciclo vital de un trabajador, a partir de las nociones de empleabilidad, seguridad y conciliación, poniendo el énfasis en la formación a lo largo de la vida, la "activación" y la organización flexible del tiempo. De acuerdo con esta visión, los mercados de trabajo modernos han dejado de ofrecer itinerarios predecibles y requieren de ajustes internos y externos para la gestión de este nuevo "mercado de riesgos" (Schmid y Schömann, 2006).

El análisis del riesgo suele abordarse desde una perspectiva individual pero los MTT lo afrontan como "riesgos sociales", referidos a una colectividad. Austria, Dinamarca y Holanda, países que la UE propone habitualmente como ejemplos de medidas de flexiguridad (Comisión de las Comunidades Europeas, 2007), han conseguido, en parte gracias a esas políticas, mantener tasas de desempleo muy inferiores y salvaguardar un buen nivel económico de sus ciudadanos, a pesar de las dificultades ocasionadas por la crisis (ver sección3). Eso sí, las diferentes rutas que han seguido en la búsqueda del equilibrio entre flexiguridad y seguridad, demuestran que no hay una vía única en el proceso. Así planteado, los MTT representarían el concepto analítico mientras que la flexiguridad aparecería como su complemento normativo.

\footnotetext{
${ }^{1}$ Se entiende aquí por activación la mejora de los incentivos para que compense trabajar.
} 
Sin embargo, gran parte de la literatura sobre flexiguridad entiende que esta concepción original de flexiguridad se ha ido desnaturalizando en favor de un mayor énfasis en la dimensión flexibilidad. Así, Keune y Jepsen (2007) consideran que la visión de la flexiguridad de la Comisión enfatiza la economía por encima de los objetivos sociales, la protección contra el riesgo y la solidaridad. Esta nueva conceptualización de la flexiguridad es, según estos autores, indisociable de la construcción del MSE, criticado por las múltiples combinaciones que tienen cabida en los estados miembros y, sobre todo, por la improvisación con la que se va conformando (Serrano Pascual, 2007; Tovar y Revilla, 2012). A pesar de los intentos de la Comisión por legitimar el modelo ante la sociedad, la visión economicista y las ambigüedades y contradicciones del MSE no solo no se superan sino que se trasladan a las políticas de flexiguridad (Jepsen y Serrano, 2006; Serrano Pascual, 2007).

Desde este mismo enfoque, y en su larga serie de documentos de debate Diskussionspapier, Tangian $(2007,2008,2009)$ ha tratado de buscar evidencias empíricas y de hacer operativos algunos indicadores sobre flexiguridad en Europa. Según Tangian (2010), desde un concepto de seguridad basado en la protección de los trabajadores atípicos y pasando por un equilibrio seguridad-flexibilidad, se ha desembocado en la adaptación de la fuerza de trabajo al empleo flexible. El investigador alemán sostiene que la flexibilidad en el empleo está directamente relacionada con la precariedad y considera, además, que una alta empleabilidad difícilmente puede conseguirse mediante el empleo flexible.

Por su parte, Madsen (2004) encuentra otras consecuencias no previstas del exceso de flexibilidad. Mercados flexiseguros como el danés, en los que existe una elevada rotación entre empleos, necesitan de una contante evaluación de la fuerza de trabajo y la ausencia de conexión entre las capacidades de los trabajadores y los criterios de los empleadores estaría expulsando gradualmente del mercado de trabajo a muchos empleados.

Tovar y Revilla (2012: 255) entienden que el concepto de seguridad "está siendo constantemente dinamitado" y puesto al servicio de la flexibilización a través de un proceso de "desapropiación" iniciado por la Comisión Europea. En similares términos se expresa Serrano Pascual (2009) quien considera que se ha producido una desvirtuación de la seguridad en su recorrido desde el significado de protección contra el riesgo hasta el de activación, con el consecuente impulso de la responsabilidad individual.

Para los MTT, sin embargo, la gestión del riesgo no se circunscribe solamente a reducirlo o hacerle frente sino también a prevenirlo. La clave estaría en formular correctamente el problema para poder diseñar medidas que reconsideren el equilibrio entre solidaridad y responsabilidad individual. Sobre la base de esta distinción terminológica, los MTT proponen alternativas al tradicional seguro de desempleo, a través de la introducción de alguna modalidad de seguro de empleo, léase seguro salarial, 
cuentas de tiempo o de formación, que protejan a los individuos durante los períodos de transición (De Gier y Van den Berg, 2006).

Por último, aunque no menos importante, el concepto de activación, fundamental en las políticas de flexiguridad, es también duramente criticado por quienes consideran que ataca directamente al corazón de los derechos sociales, convirtiendo a estos en meras oportunidades de integración laboral (Serrano Pascual, 2007). Madsen (2004), por su parte, centra sus críticas en el aumento del gasto público que conlleva la activación de los desempleados, sobre todo en épocas de recesión.

Los MTT, en cambio, estarían situando el análisis en los flujos más que en los stocks. En su condición normativa - y aquí estaríamos refiriéndonos más estrictamente a políticas vinculadas a la flexiguridad - la intención es dotarse de nuevos mecanismos institucionales que mejoren la empleabilidad tanto de los parados (transiciones integradoras) como de los ocupados (transiciones de mantenimiento de la posición) y posibiliten no solo que "compense trabajar" sino que también "las transiciones compensen" (Schmid y Schömann, 2006: 70).

La visión integradora de la teoría de los MTT se ve reforzada, además, por la oportunidad de sus propuestas, en un momento en el que la Estrategia 2020 apuesta firmemente un nuevo modelo económico y laboral que presenta mayores incertidumbres y dificultades para asegurar la estabilidad en el puesto de trabajo (Unión Europea, 2007). Sería incorrecto decir que la Estrategia Europea de Empleo ha adoptado un enfoque de los MTT, pero los estados miembros sí han introducido o están diseñando, también España, medidas como las que proponen para conseguir un Modelo Social Europeo viable (De Gier y Van den Berg, 2006).

Con este debate como trasfondo, se plantea como hipótesis de trabajo que el mercado de trabajo español es flexible solamente en su dimensión externa y más próximo a la noción de "seguridad en el puesto de trabajo" que de "seguridad en el empleo". Esto es, en nuestro país todavía siguen existiendo mayores garantías de protección frente a los despidos o modificaciones de las condiciones laborales vía contrataciones indefinidas ("seguridad en el puesto de trabajo"), a diferencia de los países "flexiseguros". En estos últimos, la certidumbre de permanencia en el trabajo ("seguridad en el empleo"), se produce a través de la formación, la activación y nuevas disposiciones como las que proponen los MTT.

Siguiendo esta hipótesis, la incompleta transición de un modelo a otro estaría favoreciendo la perpetuación de un escenario de inseguridad laboral, a partir de ese exceso de flexibilidad externa, la también llamada "mala flexibilidad" (Ruesga, 2011), un elevado desempleo estructural y un incremento del paro de larga duración durante las fases recesivas. Para Valdés Dal-Ré (2004) los sucesivos y no siempre consistentes acuerdos adoptados por los agentes sociales serían la causa de un modelo de relaciones laborales que el propio Valdés Dal-Ré y Lahera (2010:36) consideran "erráticamente flexible y sin apenas seguridad en el empleo", como consecuencia de las sucesivas reformas del mercado laboral español 


\section{Flexiguridad del mercado de trabajo español. Perspectiva comparada}

El mercado de trabajo español presenta algunas peculiaridades, como el desempleo de larga duración o las deficiencias en los sistemas de formación continua y negociación colectiva (Guillén y Gutiérrez, 2008). Pero sin duda, su rasgo más característico es la elevada y endémica temporalidad, resultado de la política laboral española de las dos últimas décadas, que ha sido responsable, en gran medida, de un gran crecimiento económico, pero obtenido a costa de fomentar la segmentación del mercado de trabajo. Como consecuencia de estas prácticas, en los últimos veinticinco años en torno al treinta por ciento de los trabajadores han estado empleados con contrato temporal (Valdés Dal-Ré y Lahera, 2010), lo que supone un tercio del total y triplica casi la media de la UE-15.

La segmentación "por tipo de contrato" se ha convertido en una de sus características distintivas, como también lo han sido las medidas flexibilizadoras basadas en la "desregulación parcial" que la han exacerbado (Polavieja, 2003:1-2). Estas características del mercado de trabajo español vendrían a constatar la existencia de un mercado primario y otro secundario en cuanto a condiciones laborales y de estabilidad en el empleo. Esto es, de empleos con elevados salarios, buenas condiciones de trabajo, estabilidad y posibilidades de ascenso, por una parte, frente a bajos salarios, escasos beneficios sociales, malas condiciones de trabajo y pocas posibilidades de ascenso, por otro (Doeringer y Piore, 1985). O de "empleos buenos y malos" en los que existe una segregación laboral atendiendo a distintos criterios (Köhler y Martín-Artiles, 2005).

Las últimas reformas laborales aprobadas en España, han pretendido seguir la senda marcada por la UE y se han mostrado abiertamente partidarias de la flexiguridad. Otra cosa es que lo hayan logrado. La Ley $3 / 2012$, de 6 de julio, por ejemplo, menciona expresamente que el "objetivo es la flexiseguridad" (BOE, 11.02.12), definida como un "conjunto coherente de medidas" que pretenden fomentar la empleabilidad de los trabajadores, la contratación indefinida y otras formas de trabajo, incentivar la flexibilidad interna en la empresa y favorecer la eficiencia del mercado de trabajo. Sin embargo, a pesar de esta hipotética apuesta por la flexiguridad, el articulado posterior demuestra mucho mayor compromiso con la dimensión flexibilidad que con la dimensión seguridad.

Con anterioridad, la reforma laboral de 2010 - Real Decreto-ley 10-2010 de 16 de junio- se presentó como una innovación en clave de flexiguridad pero, hasta ahora, sus objetivos tampoco se han cumplido. En 2011 apenas se incrementó el número total de contratos realizados con relación al año anterior, continuó aumentando la contratación temporal mientras disminuía la indefinida y los contratos de fomento, descendía el número de ocupados y se incrementaba más de un punto y medio el desempleo respecto a 2010 (INE, 2013). La mejora de la flexibilidad interna mediante la implantación de la 
reducción de jornada — Kurzarbeit ${ }^{2}$ — y la ampliación de las cláusulas de descuelgue, o la mejora de las políticas de empleabilidad basadas en la creación de la carta de servicios del desempleado y de la figura del tutor, no han sido plenamente desarrolladas ni dotadas económicamente. Otras reformas más ambiciosas, como la introducción del modelo austriaco de indemnizaciones por despido, han sido aplazadas sine die e incluso el intento de reducir la dualidad mediante la limitación del encadenamiento de contratos temporales se transformó en una ampliación de los supuestos que lo permiten (Real Decreto-ley 10/2011, de 26 de agosto).

Podría decirse que las sucesivas reformas aplicadas desde 1984 han terminado por desnivelar el equilibrio entre las dimensiones seguridad y flexibilidad en favor de esta última, condicionando el modelo de flexiguridad español. Así que, a continuación, se tratará de comparar el balance entre flexibilidad y seguridad del mercado de trabajo español con el de sus pares, el resto de estados miembros de la UE, mediante la utilización de algunos indicadores que se han considerado útiles para la medición de ambas dimensiones. Para ello se ha acudido en primera instancia a datos secundarios, procedentes de diversas fuentes, un paso imprescindible para situar el debate sobre la flexiguridad en nuestro país. A continuación, en el epígrafe de resultados, se realiza un análisis ya con datos primarios.

\subsection{Indicadores de flexibilidad en España}

Para que la discusión sobre las características del mercado laboral español no quede reducida a un debate teórico, en los siguientes apartados se han tratado de reforzar estas aportaciones con datos empíricos sobre el grado de flexiguridad del mercado laboral español. Se confronta la situación de España con la del resto de países de la UE-27, y se destaca la realidad de aquellos que más y mejor están trabajando las políticas de flexiguridad.

A partir de la noción de rigidez/flexibilidad del mercado laboral, se van a emplear varios indicadores para tratar de medir el grado de flexibilidad del caso español. Por un lado se utilizarán algunos indicadores de flexibilidad externa, como el porcentaje de rotación en el empleo, o las tasas de contratación y finalización de contratos. Para evaluar el grado de implantación de medidas de flexiguridad interna, se utiliza como indicador el número de expedientes de reducción de jornada.

${ }^{2}$ El Kurzarbeit es una medida laboral anti crisis que podría traducirse al español como trabajo corto o trabajo reducido. En los últimos años se ha popularizado en España pues es una de las medidas que mejor han funcionado en Alemania para mantener la tasa de desempleados en los niveles anteriores a la recesión. 


\subsubsection{Disposiciones contractuales flexibles: flexibilidad externa}

La discusión sobre la rigidez del mercado laboral es un tema recurrente, que cobra actualidad especialmente en épocas de crisis. Sin embargo, las cifras son interpretadas por los distintos actores sociales de tal forma que resulta difícil conocer el grado de flexibilidad/inflexibilidad real del mercado de trabajo español.

Debido a que la flexibilidad/rigidez del mercado de trabajo español se asienta sobre conceptos de límites difusos, se presenta a continuación el gráfico 1 que puede otorgar más nitidez al asunto. Se han utilizado datos del período 2002-2007, para evitar cualquier "contaminación" producida por la actual crisis de empleo. Como puede apreciarse, España tuvo entre 2002 y 2007 la tasa de rotación más alta de los países de su entorno, solamente superada por Dinamarca, pero con la particularidad de que la danesa es una rotación fundamentalmente voluntaria, que obedece a la facilidad para encontrar otro empleo en un mercado altamente dinámico (Andersen y Svarer, 2007).

GRÁFICO 1:CONTRATACIONES, ROTACIÓN, FINALIZACIONES DE CONTRATO 2002-2007 (\% DEL EMPLEO)

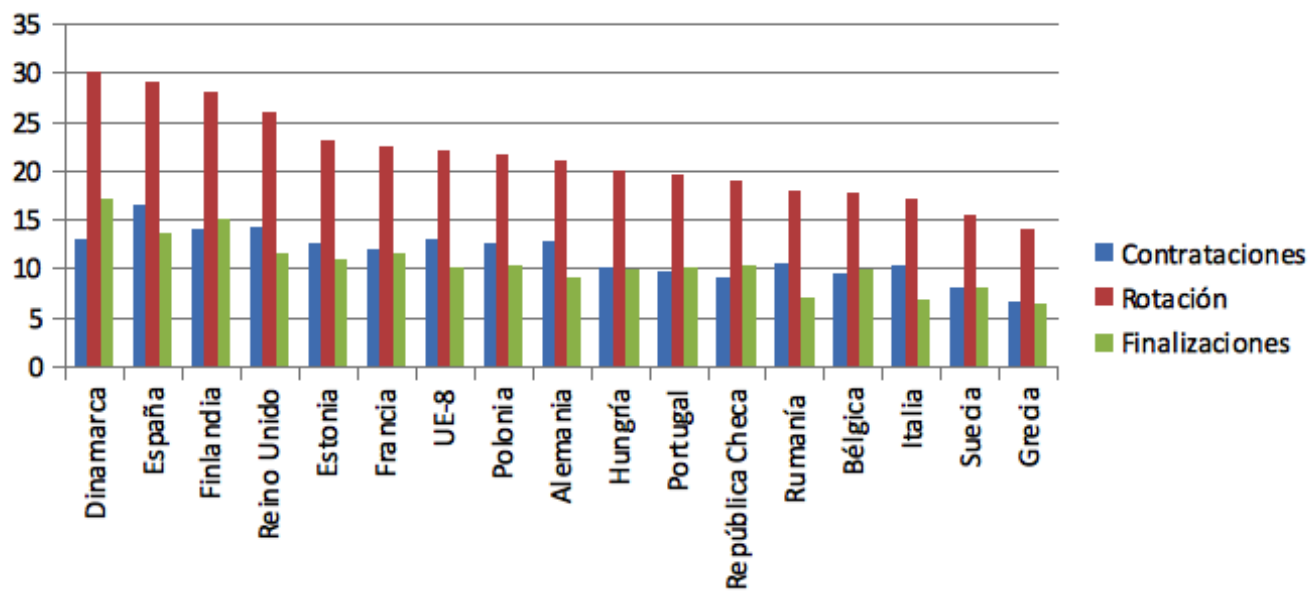

Fuente: Elaboración propia, a partir de European Commission (2009) Employment in Europe 2009, Hirings, separations and labour turnover.

También se puede observar cómo la alta tasa de contratación existente en nuestro país $(15 \%)$ era más elevada que la de cualquiera de los mercados laborales en comparación. Por último, por lo que se refiere al porcentaje de contratos finalizados, también España se sitúa a la cabeza, concretamente en tercer lugar, solamente superada otra vez por Dinamarca y por Finlandia, que poseen políticas activas que favorecen una rápida recolocación de los trabajadores desempleados. 


\subsubsection{Disposiciones contractuales flexibles: flexibilidad interna}

Una medida de flexibilidad interna existente en España pero apenas utilizada hasta ahora, es la que permite que las empresas apliquen reducciones temporales de jornada como alternativa a los despidos colectivos. Es el equivalente al Kurzarbeit alemán, solo que en el caso español conlleva una tramitación mucho menos ágil. Además, el marco legislativo en nuestro país es más restrictivo, puesto que solo es aplicable en el marco de un Expediente de Regulación de Empleo. Esto supone dejar fuera a las empresas de menos de diez trabajadores, ${ }^{3}$ que constituyen más del $95 \%$ del total (INE, 2013) y la reducción de jornada debe ser de al menos el $33 \%$, con una minoración de salario equivalente.

Gráfico2: Evolución de Los EXPEDIENTES de REGULACIÓN DE EMPLEO (NúMERO TOTAL DE EXPEDIENTES)

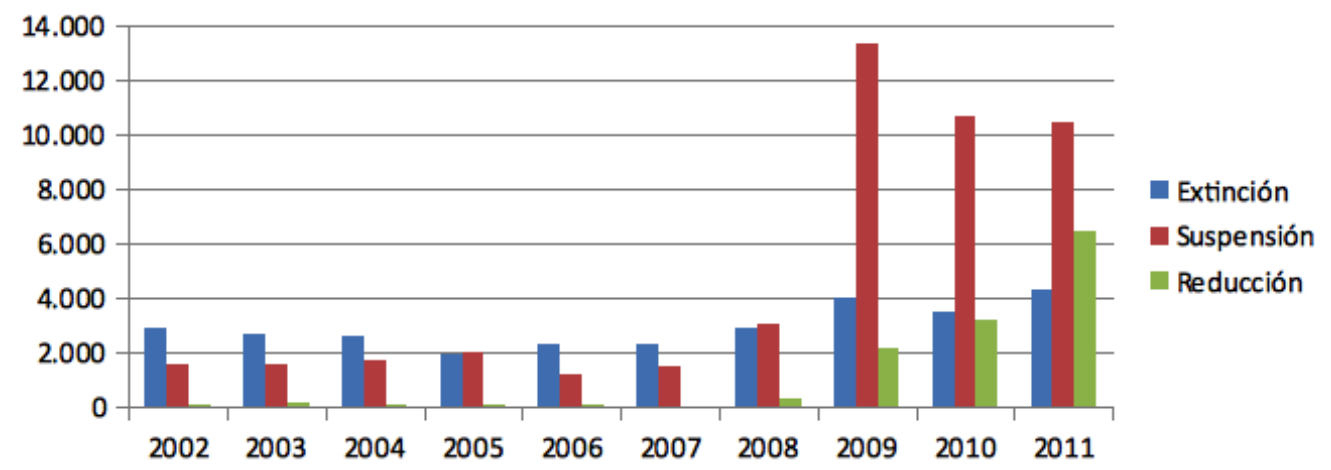

Fuente: Elaboración propia, a partir de Ministerio de Empleo y S. Social (2012), Estadística de regulación de Empleo, datos anuales.

Por lo demás, con algunas diferencias, como quién se hace cargo de las cotizaciones a la S.S., o el consenso entre los agentes sociales para su aplicación, el funcionamiento es similar al del Kurzarbeit alemán. Estas medidas fueron incluidas en la Ley 27/2009 ante la escasa utilización del "Kurzarbeit español". El resultado es que desde 2009 se han reducido los expedientes de suspensión a favor de los de reducción, mientras que se han mantenido bastante estables los despidos colectivos, como se puede ver en el gráfico 2 .

Este cambio de tendencia ha permitido el mantenimiento de muchos puestos de trabajo que de otra forma se hubieran destruido, pero tiene otras ventajas, como una

3 Un Expediente de Regulación de Empleo (ERE) tiene que afectar al menos a 10 empleados en empresas de menos de cien trabajadores. 
menor aportación del Estado por prestaciones de desempleo o la mayor capacidad de las empresas en crisis de retener a sus mejores trabajadores hasta que la situación económica mejore. Los trabajadores, por su parte, ven reducido mínimamente su poder adquisitivo, mantienen intactas las cotizaciones a la S.S. y pueden aprovechar el tiempo disponible para formarse mejor y para conciliar.

A la vista de lo expuesto, podría decirse que el exceso de rotación conlleva un elevado grado de incertidumbre en un mercado tan poco dinámico como el español. En el mercado danés, por ejemplo, resulta mucho más aceptable este exceso de flexibilidad externa, a pesar de las consecuencias no previstas que según Madsen (ver sección 1) puede comportar. E incluso el propio Madsen (2004) considera que es un precio razonable a pagar por el alto grado de eficiencia del mercado de trabajo danés. Parece, pues, más razonable acometer una modernización del mercado laboral español mejorando aspectos organizativos y funcionales de las empresas como la flexibilización interna, que podría redundar, desde el punto de vista empresarial, en una mayor adaptabilidad a las fluctuaciones de los ciclos económicos. Y desde la perspectiva del trabajador, ayudaría al mantenimiento de puestos de trabajo en épocas de crisis.

\subsection{Indicadores de seguridad en España}

Por lo que respecta a la dimensión seguridad, servirán como indicadores la tasa de temporalidad de los trabajadores de nuestro país - (in)seguridad en el puesto de trabajo-, el gasto en políticas activas - seguridad en el empleo-y la tasa de desempleo de larga duración - (in)seguridad de rentas-.

\subsubsection{Temporalidad: (in)seguridad en el puesto de trabajo}

Gráfico 3: TASA de temporalidad En España y la UE (2007-2012)

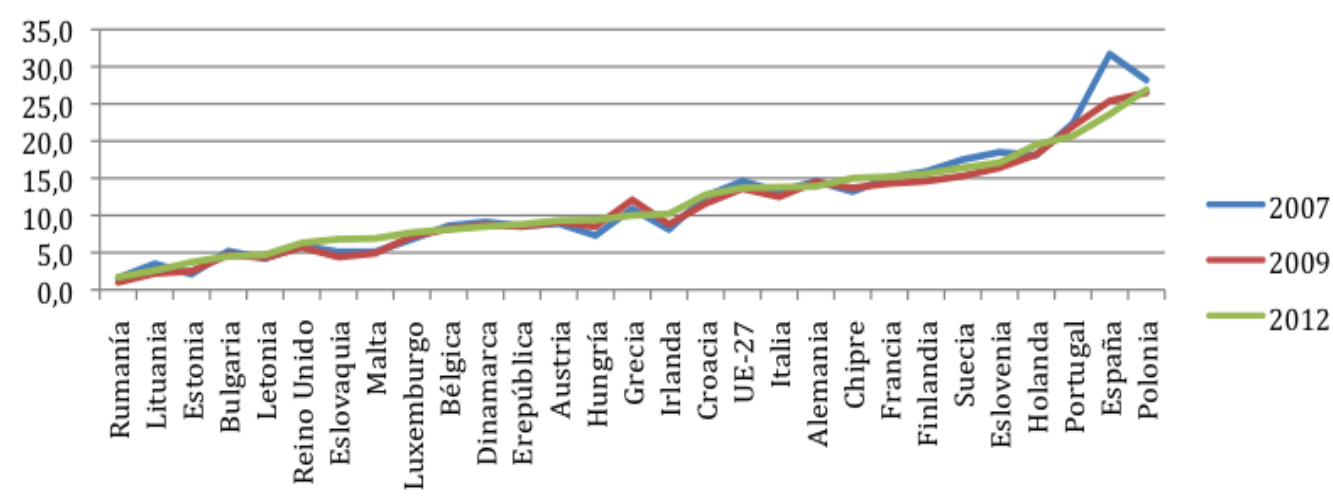

Fuente: Elaboración propia, a partir de Eurostat 
Según el Ministerio de Economía, en 2006 España había creado casi el 40\% del empleo nuevo de la zona euro. Sin embargo, a finales del 2012, el desempleo en España se situaba en el $25,0 \%$ de la población activa —era el 8,3 \% en 2007—, lo que situaba al país como el primero de la UE-27 con mayor porcentaje de paro. Además, la tasa de temporalidad registrada en España es de las más elevadas de la UE, solo superada por Polonia, muy por encima de los países de su entorno y, lo que es peor, sostenida en el tiempo.

Pese a que la temporalidad ha descendido en España desde el 31,7\% que registraba en 2007 hasta el 23,6 con el que se cerró 2012 (gráfico 3), esto no significa que se esté resolviendo el problema de la eventualidad en España sino que la masiva destrucción de empleo en estos dos años se ha concentrado fundamentalmente en los trabajadores temporales, más expuestos por sus menores costes de despido.

\subsubsection{Activación y formación: seguridad en el empleo}

Otro componente básico de la flexiguridad son las políticas activas, que requieren una importante inversión de recursos públicos, por lo que se precisa de una buena planificación e implementación que asegure la rentabilidad de dichas medidas y el cumplimiento último de sus objetivos de reducción del desempleo (BBVA Research, 2011).

Las políticas activas tienen su mirada puesta en la recualificación de los empleados en paro de forma que puedan acortarse los plazos en las transiciones desde el desempleo a la actividad, o lo que Wilthagen y Tros (2004) llaman en su clasificación "seguridad en el empleo". Sin embargo, todavía existen muchas carencias en cuanto a políticas de activación en España, lo cual dificulta tanto el acceso al mercado de trabajo como las transiciones de entrada y salida de él. Y los datos ponen en duda la efectividad de las políticas implementadas (Mato y Cueto, 2008), o al menos el esfuerzo realizado hasta el momento se muestra insuficiente.

De acuerdo con Eurostat, España se encontraba en 2007 por encima de la media comunitaria en gasto - aunque mejor sería llamarlo inversión - en políticas activas, con un $0,63 \%$ del PIB frente al $0,46 \%$ de la UE-27, y cerca del $0,72 \%$ de Holanda. E incluso invirtió más que Austria $-0,51 \%$ - o Alemania - $0,47 \%$ - No obstante, si lo que comparamos es la inversión en políticas activas por persona participante en estos planes, como se observa en el gráfico 4, la cantidad que dedicaba España por persona ya no se encuentra entre las más altas de Europa y muy lejos de los países que la Comisión (Comisión de las Comunidades Europeas, 2007) propone como modelos de flexiguridad, que se encuentran muy por encima de la media de la UE-27. E incluso la proporción había disminuido en España en 2010 con respecto al gasto de 2007, a pesar de haberse producido en ese tiempo un incremento de casi doce puntos en la tasa de desempleo. 
GrÁFico 4: GASTO EN POLÍTICAS ACTIVAS POR PERSONA QUE BUSCA EMPLEO (EN PARIDAD DE PODER ADQUISITIVO)

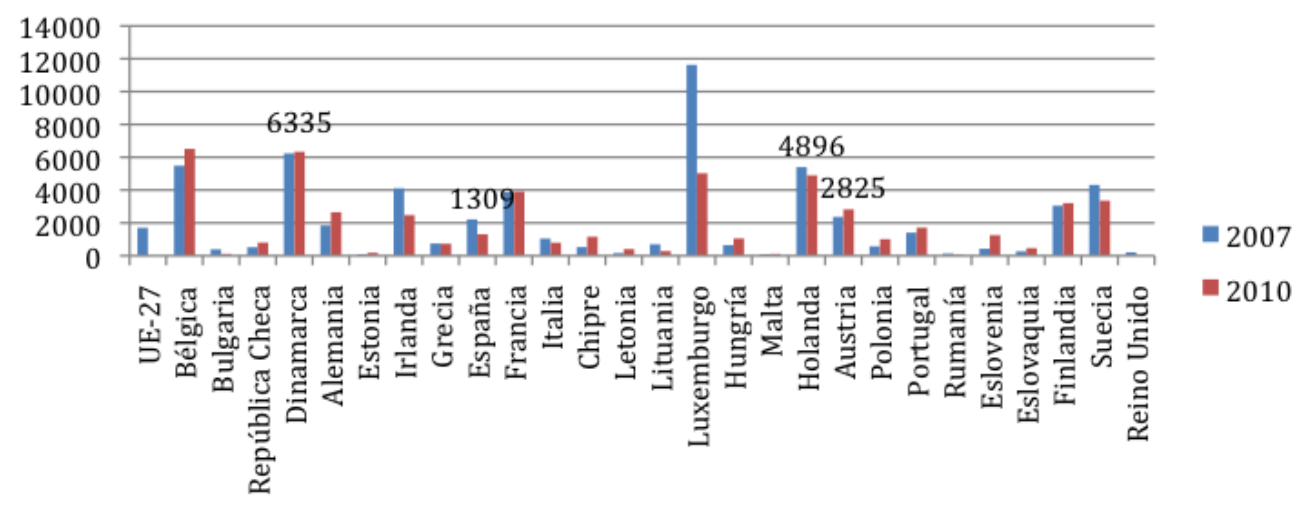

Fuente: Elaboración propia, a partir de Eurostat.

\subsubsection{Desempleo: (in)seguridad de rentas}

Las políticas de flexiguridad han reportado a algunos países unos excelentes resultados en materia de empleo y seguridad de rentas, entre ellos a Austria, Dinamarca y Holan$\mathrm{da}$, que han conseguido mantener bajos niveles de desempleo $(4,3 \%, 5,3 \%$ y $7,5 \%$ en 2012, respectivamente) a pesar de las turbulencias económicas. Sin embargo, España experimentó un vertiginoso incremento, entre 2007 y 2010, desde el 8,3\%, el más bajo de su historia reciente, hasta el $21,7 \%$, doce puntos por encima de la media de la UE-27, lo que demuestra el mal funcionamiento del mercado laboral en su conjunto (Koster et al., 2011).

Esta variabilidad es todavía más apreciable en la evolución del desempleo de larga duración (gráfico 5), un buen indicador de cómo el mercado laboral no es capaz de afrontar los cambios en el largo plazo (ibídem). Los datos del gráfico 5 no están acumulados, sino que cada color corresponde a un año y las etiquetas de datos se refieren a cifras del último año recogido, 2012. Se ha optado por este modelo de gráfico para reflejar mejor los desequilibrios por países entre los años de expansión y contracción económica.

En cualquier caso, en este apartado también los datos son claros: mientras en Austria, Holanda o Dinamarca el desempleo de larga duración suponía en 2012 entre el 1\% y el $2 \%$, en España se superaba el $11 \%$, más del doble de la media comunitaria. Y se observan grandes desequilibrios entre los años de expansión y los de contracción de la economía, un efecto que no se aprecia en los países flexiseguros, en donde el paro de larga duración permanece constante y en porcentajes muy bajos ante los cambios de ciclo económico. 
GrÁfico 5: TASA DE DESEMPLeO DE LARGA DURACión (2007-2010)

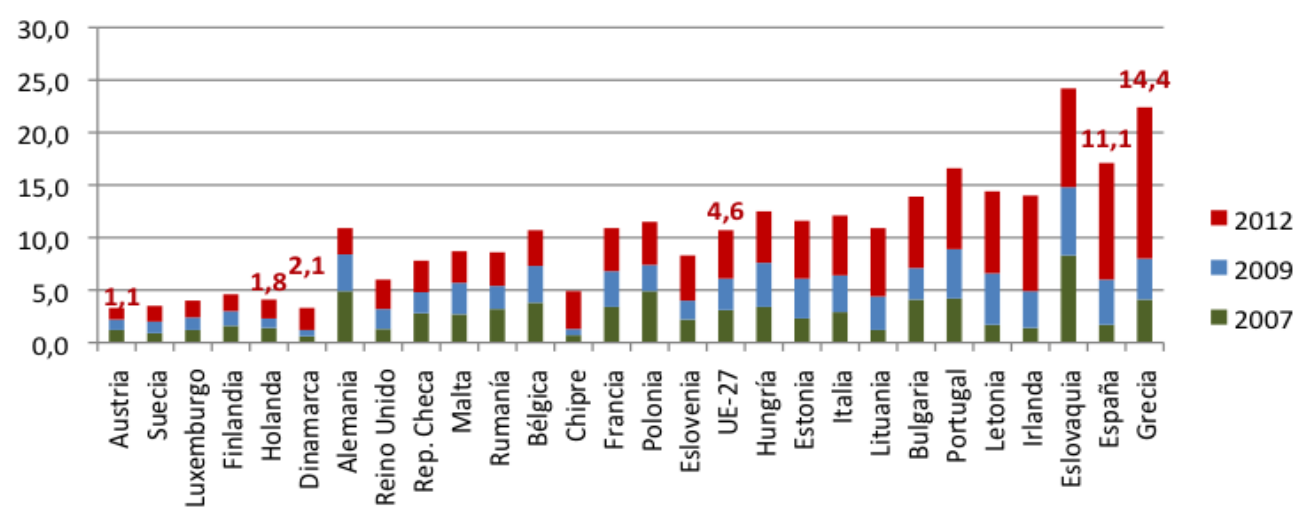

Fuente: Elaboración propia, a partir de datos de Eurostat (2012).

Como conclusión de este apartado, podríamos decir que todos los datos reflejan que España tiene problemas en varios componentes de su mercado de trabajo, que la flexiguridad podría ayudar a resolver. En cuanto a la flexibilidad, parece que existe demasiada en su versión externa, mientras que las empresas carecen de los mecanismos necesarios para implantar flexibilidad interna en sus organizaciones.

Por lo que respecta a la dimensión seguridad, se ha evidenciado la presencia de una gran incertidumbre tanto en el trabajo como en el empleo, como lo demuestran las altas tasas de paro y las elevadas cifras del desempleo de larga duración. Además, la protección gubernamental se centra en la protección pasiva y descuidan la activa. Las políticas de activación resultan controvertidas, tanto por el componente de responsabilidad individual que comporta como por el gasto público que conlleva. Sin embargo, algunos de sus detractores, como Madsen (2004) reconocen su utilidad económica y política durante décadas y en situaciones adversas como las acaecidas durante las crisis del petróleo.

\section{Metodología del estudio empírico}

La metodología empleada en el presente artículo contempla, en primer lugar, un análisis de algunas fuentes estadísticas disponibles sobre el mercado laboral con las que poder construir algunos indicadores que nos aporten un mejor conocimiento del grado de flexiguridad del mercado laboral español. Para esta parte, que se desarrolla en la sección dedicada al estado de la cuestión de la flexiguridad en España, se han utilizado como indicadores datos secundarios, procedentes esencialmente de la EPA, los registros del MTAS o Eurostat. El empleo de datos secundarios se justifica, en primer 
lugar, por la importancia de plantear cuál es la situación de partida del mercado laboral español en materia de flexiguridad. Y también por la necesidad de establecer unos indicadores en las dos dimensiones del término, flexibilidad y seguridad, que sirvan de base para la elaboración de un método operativo de trabajo para el análisis de datos que se realiza en el apartado de resultados.

En segundo lugar, para salvar las limitaciones propias de los datos secundarios, se han estudiado otras fuentes alternativas que permitan la realización de una investigación ya con datos primarios. Este trabajo se realiza en el mencionado apartado de resultados. Para esta sección, se ha realizado un análisis mediante la explotación de la Muestra Continua de Vidas Laborales (MCVL), que se obtiene a partir de registros administrativos y cuyo funcionamiento se explica en el siguiente epígrafe. La MCVL posibilita conocer las trayectorias laborales de los trabajadores españoles, lo que casa muy bien con la visión dinámica del mercado de trabajo de los MTT. La utilización de esta fuente de datos, no solo permitirá la confirmación de algunas hipótesis relacionadas con las transiciones laborales, sino el análisis empírico de otras variables que, como la temporalidad o el tipo de jornada, están muy presentes en la teoría de los MTT.

\subsection{La Muestra Continua de Vidas Laborales}

La fuente de datos elegida para el análisis con datos primarios, la MCVL, es la única que posibilita conocer en detalle las trayectorias laborales de los trabajadores españoles debido a la procedencia de sus datos, los registros de la Seguridad Social (S.S.). La MCVL ofrece información sobre más de un millón de personas y tiene una visión tanto estática como dinámica de todas las personas que han estado afiliadas o recibiendo pensiones contributivas o prestaciones por desempleo en algún momento del año de referencia, sea cual sea el tiempo que hayan permanecido en dicha situación.

Disponible desde el año 2004, la MCVL se configura como una sucesión de muestras anuales autocontenidas pero su diseño garantiza que un individuo que ha sido seleccionado en una muestra también lo sea en las posteriores. Se obtiene a partir de un muestreo aleatorio simple no estratificado, equivalente al $4 \%$ de la población de referencia, la información está disponible en microdatos y la unidad de análisis puede ser el "episodio de cotización" (Toharia y Cebrián, 2007) o la persona.

Existen dos formas de abordar la muestra. Una transversal o estática, mediante la utilización de una sola ola, mejor para el corto plazo. La segunda posibilidad es el análisis longitudinal o dinámico, para lo que se necesita trabajar con los datos hasta convertirlos en una base de datos tipo panel aunque con algunas peculiaridades, pues los procesos de entrada y salida alejan a la MCVL de un panel clásico.

La MCVL ofrece numerosas ventajas para la investigación. Una de sus utilidades es la facilidad para conocer con exactitud el inicio y fin de todos los episodios laborales de los individuos seleccionados. La MCVL también permite analizar el momento de 
la entrada en el mercado de trabajo, una circunstancia influyente en la trayectoria laboral posterior - scarring efects - (ibídem).Y una tercera ventaja, de la que se puede obtener un indudable rendimiento, es que la MCVL ofrece un periodo de análisis más largo que el de la Encuesta de Población Activa (EPA), permitiendo, además, estudiar la trayectoria anterior.

Así que la MCVL, a pesar de la dificultad operacional que entraña el análisis de transiciones, se muestra como una herramienta fundamental que ofrece una información valiosísima para una investigación sobre flexiguridad.

\subsection{Plan de trabajo $y$ variables utilizadas}

En el presente artículo se ha desarrollado un análisis de transiciones entre las distintas situaciones laborales por las que han atravesado los trabajadores entre 2007 y 2010, aprovechando la información existente en los registros de la S.S. Se optó por iniciar el análisis en 2007 para aislar la posible influencia que sobre los datos pudiera tener la reforma laboral de 2006, fundamentalmente en lo referente al cambio de la pauta de estabilidad contractual que pudieran haber introducido los contratos iniciales bonificados previstos en la Ley 43/2006. Pero también por la oportunidad de realizar un análisis en una etapa de crisis, pues en estos momentos de dificultad para el empleo es donde más apreciables son los efectos de las políticas de flexiguridad.

Para obtener la muestra se seleccionaron todas aquellas personas que durante el año 2007 habían tenido episodios de empleo de más de tres meses. Se descartó a las que habían trabajado menos de ese período de tiempo por considerarse que no cumplían los criterios necesarios para incluirlos en una investigación que trata de analizar trayectorias de empleo desde una perspectiva de flexiguridad. El total de episodios recogidos mediante este procedimiento alcanza los 10.992.222, que corresponden a 782.783 personas. De éstas, 451.109 son hombres $(57,6 \%)$ y 331.480 mujeres $(42,3 \%)$

El análisis de transiciones se configura a partir de las distintas situaciones laborales por las que han atravesado los trabajadores entre 2007 y 2010. Para llevar a cabo este análisis, se recodificaron algunas variables y se crearon otras nuevas, de forma que pudiera hacerse un estudio detallado de las trayectorias laborales y de las distintas categorías en las que se ubican los trabajadores en los años que abarca la muestra, esto es, indefinido, temporal, autónomo, desempleado o fuera de muestra. Las tres primeras categorías son claras y recogen lo que habitualmente se entiende por trabajador con contrato indefinido, temporal o autónomo. Pero no así las dos últimas, respecto a las que hay que hacer algunas aclaraciones.

Debido a la metodología utilizada por la MCVL, debemos entender por desempleado a aquel trabajador que ha perdido su empleo y está recibiendo algún tipo de prestación contributiva. Por eso, los datos referentes al paro que aparecen en algunas tablas del capítulo de resultados no reflejan a quienes han perdido su empleo pero no 
tienen derecho al cobro de prestaciones, una de las razones por las que se ha añadido la categoría denominada fuera de muestra. En esta última categoría se incluye a la población muestral que estando empleada al menos tres meses en 2007 no se encuentra registrada en las sucesivas olas en ninguna de las otras categorías (indefinido, temporal, autónomo, desempleado) bien porque ha salido del mercado laboral, bien porque, aun estando en él, se encuentra en situación de desempleo y sin derecho a prestación contributiva.

\section{Resultados: análisis de transiciones}

Para esta parte del estudio se han realizado comparativas bianuales, de tal forma que las transiciones intercategoriales se reflejen en las tablas 1, 2 y 3 . Por lo que se refiere a la situación de los indefinidos, observamos dos categorías, los que se mantienen en el mismo episodio de empleo indefinido y aquellos que aunque continúan en años posteriores a 2007 con una modalidad contractual de este tipo, lo hacen en un episodio distinto al de 2007. Entre 2007 y 2008 se mantienen en el mismo episodio de contrato indefinido el $65,4 \%$ de los trabajadores, un porcentaje que se eleva hasta el $83,6 \%$ en el período 2008-2009 y asciende todavía más en el bienio 2009-2010. Podríamos decir que el mejor seguro contra la inestabilidad laboral es mantenerse en el mismo episodio de empleo indefinido que se tenía en 2007, porque si se pierde éste, aunque el trabajador o la trabajadora recuperen el empleo a través de un contrato indefinido, tienen muchas probabilidades de que éste sea muy breve, tanto que no le alcance para adquirir derecho a recibir una prestación por desempleo.

Observamos qué ocurre en las transiciones para quienes tienen un contrato indefinido diferente al de 2007 en el período 2008-2010, una categoría que hemos denominado simplemente indefinido. Entre 2007 y 2008 se mantuvieron con un contrato indefinido - aunque en diferente episodio- el 7,2\%; un 10,0\% entre 2008 y 2009; un 11,8\% en el período 2009-2010. Durante el cuatrienio analizado, tampoco se incrementó en demasía el trasvase entre indefinido y temporal, 4,1\%, 3,1\% y 3,6\%, respectivamente, para los bienios 2007-2008, 2008-2009 y 2009-2010, ni entre indefinido y desempleado, $10,3 \%, 13,4 \%$ y $11,7 \%$ respectivamente. Entonces, ¿qué sucedió con el resto? Pues que el $12,9 \%$ de los trabajadores que tenían un episodio de empleo indefinido en 2007 se encontraban fuera de muestra en 2008. Pero es que los porcentajes se incrementaron de forma exponencial entre 2008-2009 y 2009-2010 para aquellos cuya situación contractual era distinta a la que tenían en 2007. Hasta un 73\% de los indefinidos el año anterior se encontraban fuera de muestra en el siguiente, siempre hablando del grupo de trabajadores que firmaron un contrato indefinido con posterioridad a 2007. Parece aquí trascendental estar contratado de forma indefinida en el momento en el que comenzó la crisis, pues cerca de un $90 \%$ de estos trabajadores se mantenían en la misma 
situación en 2008, mientras que casi tres de cada cuatro los nuevos indefinidos de ese año se encontraban fuera de muestra en 2009. Por tanto, encontramos a partir de 2008 una elevadísima cantidad de contratos indefinidos de tan corta duración que a su rescisión dejan sin prestación de desempleo a los trabajadores.

Para analizar la situación de los trabajadores temporales hemos operado de la misma manera que con los indefinidos, distinguiendo entre quienes conservaron el mismo episodio de contrato temporal que en 2007 (mismo episodio temporal) y quienes se mantuvieron en esta misma modalidad contractual pero en un episodio distinto (temporal). Entre los primeros, encontramos que permanecieron en el mismo episodio el $23,5 \%$ entre 2007 y 2008 , el $27,4 \%$ en el período $2008-2009$ y ascendieron hasta el $33,9 \%$ en el bienio 2009-2010. Como el trasvase entre temporal e indefinido fue tan solo del $4 \%$ o el $5 \%$ en todos los momentos temporales, lo interesante en este caso es observar cómo se han comportado el resto. Y vemos que un porcentaje elevado, en torno al $30 \%$ en todos los bienios, ha terminado en el desempleo y que a otros tantos los hemos perdido en la muestra. Concretamente, el $25,5 \%$, el $37,3 \%$ y el 30,2\% se encuentran fuera de muestra. En todo caso, en los bienios 2008-2009 -el peor a tenor de los datos- y 2009-2010, si comparamos el trasvase temporal-desempleo/fuera de muestra e indefinido-desempleo/fuera de muestra, las ventajas se redujeron para los contratados de forma indefinida respecto a quienes lo fueron de manera temporal, al menos en cuanto a estabilidad en el empleo.

\section{TABLA 1: Transiciones ENTRE CATEgORÍAS 2007-2008}

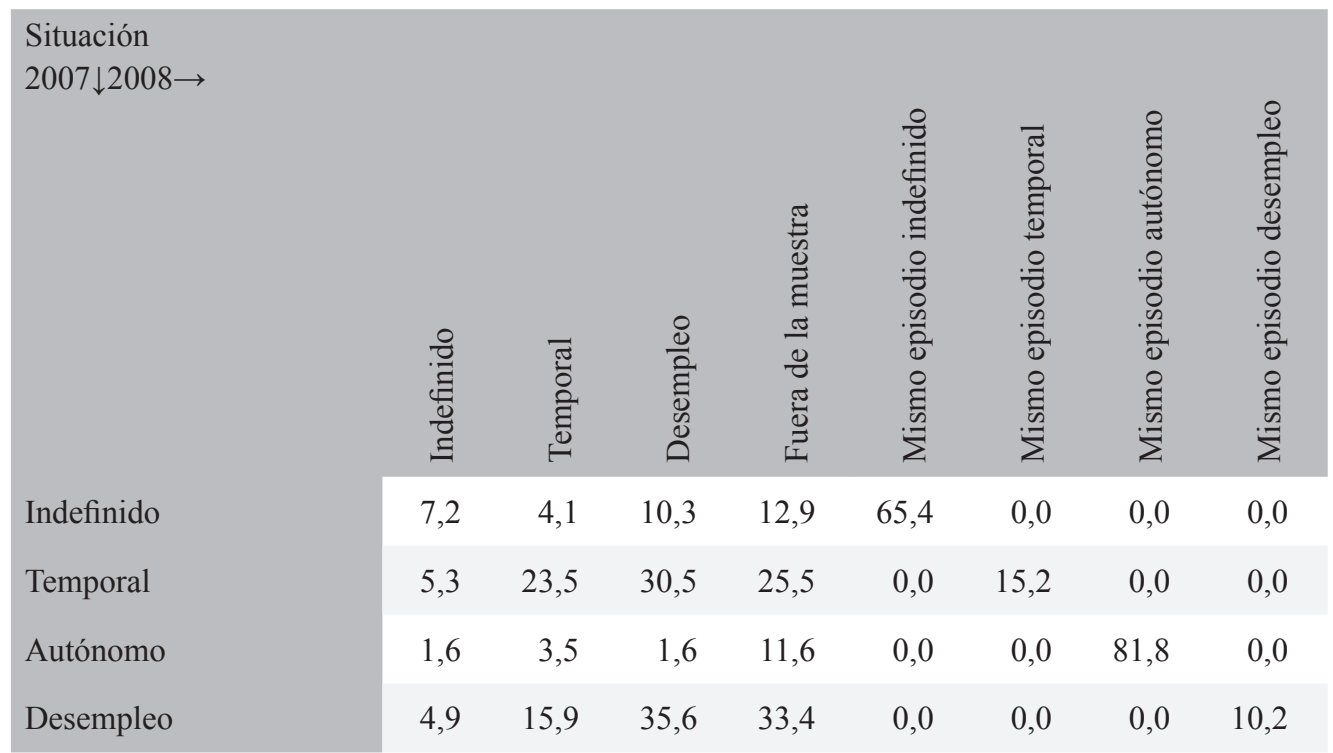

Fuente: Elaboración propia a partir de la MCVL. 


\begin{tabular}{|c|c|c|c|c|c|c|c|c|}
\hline $\begin{array}{l}\text { Situación } \\
2008 \downarrow 2009 \rightarrow\end{array}$ & 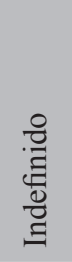 & 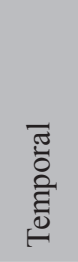 & 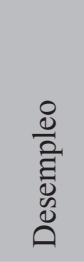 & $\begin{array}{l}\frac{\pi}{0} \\
\frac{\pi}{0} \\
\frac{\pi}{0} \\
0 \\
\stackrel{0}{\Xi}\end{array}$ & 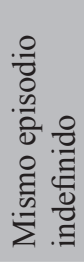 & 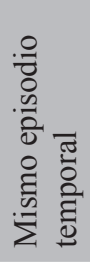 & 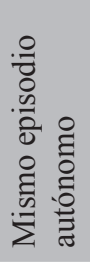 & 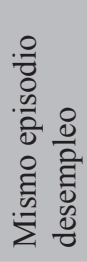 \\
\hline Indefinido & 10,0 & 3,1 & 13,4 & 73,5 & 0,0 & 0,0 & 0,0 & 0,0 \\
\hline Temporal & 4,8 & 27,4 & 30,5 & 37,3 & 0,0 & 0,0 & 0,0 & 0,0 \\
\hline Desempleo & 4,1 & 14,4 & 49,1 & 32,4 & 0,0 & 0,0 & 0,0 & 0,0 \\
\hline Fuera de la muestra & 6,3 & 6,5 & 12,7 & 74,5 & 0,0 & 0,0 & 0,0 & 0,0 \\
\hline Mismo episodio indefinido & 3,9 & 0,7 & 7,2 & 4,6 & 83,6 & 0,0 & 0,0 & 0,0 \\
\hline Mismo episodio temporal & 2,4 & 6,0 & 11,4 & 9,1 & 0,0 & 71,2 & 0,0 & 0,0 \\
\hline Mismo episodio autónomo & 0,8 & 1,5 & 0,3 & 7,4 & 0,0 & 0,0 & 89,9 & 0,0 \\
\hline Mismo episodio desempleo & 0,2 & 0,6 & 7,7 & 10,3 & 0,0 & 0,0 & 0,0 & 81,3 \\
\hline
\end{tabular}

Fuente: Elaboración propia a partir de la MCVL.

TABla 3: Transiciones ENTRE CATEGORÍAs 2009-2010

\begin{tabular}{|c|c|c|c|c|c|c|c|c|}
\hline $\begin{array}{l}\text { Situación } \\
2009 \downarrow 2010 \rightarrow\end{array}$ & $\begin{array}{l}\text { 윰 } \\
\text { 륨 } \\
\text { 음 }\end{array}$ & 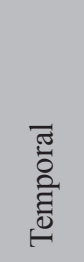 & 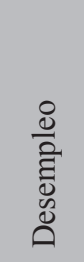 & 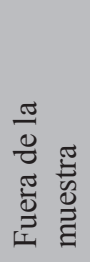 & 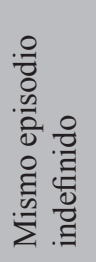 & 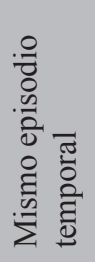 & 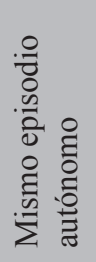 & 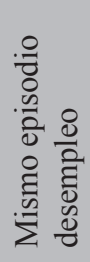 \\
\hline Indefinido & 11,8 & 3,6 & 11,7 & 73,0 & 0,0 & 0,0 & 0,0 & 0,0 \\
\hline Temporal & 4,4 & 33,9 & 31,4 & 30,2 & 0,0 & 0,0 & 0,0 & 0,0 \\
\hline Desempleo & 3,6 & 13,9 & 55,9 & 26,6 & 0,0 & 0,0 & 0,0 & 0,0 \\
\hline Fuera de la muestra & 4,3 & 5,1 & 9,0 & 81,6 & 0,0 & 0,0 & 0,0 & 0,0 \\
\hline Mismo episodio indefinido & 4,3 & 0,6 & 5,6 & 2,6 & 86,9 & 0,0 & 0,0 & 0,0 \\
\hline Mismo episodio temporal & 1,9 & 4,8 & 6,3 & 8,1 & 0,0 & 78,9 & 0,0 & 0,0 \\
\hline Mismo episodio autónomo & 0,6 & 1,1 & 0,2 & 5,8 & 0,0 & 0,0 & 92,3 & 0,0 \\
\hline Mismo episodio desempleo & 0,1 & 0,3 & 5,0 & 9,1 & 0,0 & 0,0 & 0,0 & 85,5 \\
\hline
\end{tabular}

Fuente: Elaboración propia a partir de la MCVL. 
TABLA 4: Transiciones ENTRE CATEGORÍAs 2007-2010

\begin{tabular}{|c|c|c|c|c|c|c|c|c|}
\hline $\begin{array}{l}\text { Situación } \\
2007 \downarrow 2010 \rightarrow\end{array}$ & $\begin{array}{l}\frac{0}{0} \\
\stackrel{0}{\Xi} \\
\frac{0}{0} \\
\Xi\end{array}$ & 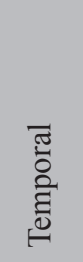 & 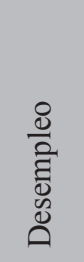 & 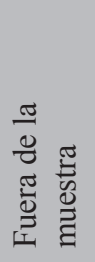 & 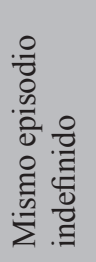 & 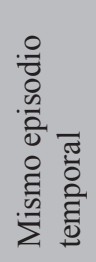 & 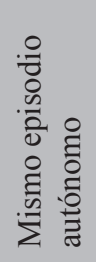 & 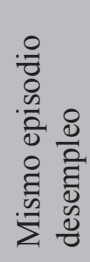 \\
\hline Indefinido & 5,4 & 3,9 & 13,1 & 30,2 & 47,3 & 0,0 & 0,0 & 0,0 \\
\hline Temporal & 2,9 & 14,1 & 27,4 & 47,2 & 0,0 & 8,4 & 0,0 & 0,0 \\
\hline Autónomo & 1,3 & 3,8 & 3,9 & 24,8 & 0,0 & 0,0 & 66,2 & 0,0 \\
\hline Desempleo & 2,8 & 9,8 & 29,9 & 50,5 & 0,0 & 0,0 & 0,0 & 7,0 \\
\hline
\end{tabular}

Fuente: Elaboración propia a partir de la MCVL.

A continuación vamos a analizar cuáles fueron las transiciones que llegan a realizar los parados entre los años de referencia, teniendo en cuenta de nuevo que, como en las categorías anteriores, también se distingue entre mismo episodio de desempleo y desempleo.

La evolución del paro se comprueba negativa sea cual sea el bienio y las categorías que analicemos. Así, en 2008 se mantuvieron en situación de desempleo el 35,6\% de quienes ya lo estaban en 2007, una cifra que se incrementó hasta el $49,1 \%$ para el bienio 2008-2009 y al 55,9\% en 2009-2010. Con el agravante de que más del $80 \%$ de los parados de los ejercicios 2008-2009 y 2009-2010 se encontraban en el mismo evento de desempleo — parados de larga duración, por tanto — cuando entre 2007 y 2008 solo el 10,2\% seguía en el mismo episodio de paro. Y no son menos negativas las cifras que ofrecen el resto de transiciones desde el paro, pues menos del 5\% de las personas desempleadas consiguieron firmar un contrato indefinido en los bienios comparados y solo entre el $14 \%$ y el $16 \%$ consiguieron transitar del desempleo a la temporalidad. Además, al menos una cuarta parte de los parados se quedaron sin prestaciones con relación al año anterior, pues salieron de la muestra el $33,4 \%$, el $32,4 \%$ y el $26,6 \%$ respectivamente en los bienios 2007-2008, 2008-2009 y 2009-2010.

Es posible que debido a las dificultades que hemos visto para transitar entre las distintas categorías laborales por cuenta ajena, haya un porcentaje importante de personas que se hayan decantado por el trabajo por cuenta propia, la categoría más estable de todas las que analizamos Según se puede comprobar en las tablas 1, 2 y 3, en 2008 conservaban el mismo episodio de autónomo el $81,8 \%$ de aquellos que partían en esta situación en 2007, manteniéndose e incluso mejorando la estabilidad en el período 2008-2009 (89,9\%) y en el bienio 2009-2010 (92,3\%). Y prueba del escaso interés que 
despertaba en los autónomos cambiar su situación laboral —o de las dificultades para transitar - es que las transiciones desde esta categoría a las restantes son estadísticamente poco relevantes. Tan solo es apreciable el porcentaje de autónomos que salen de la muestra, $11,6 \%, 7,4 \%$ y 5,8\% para los bienios $2007-2008,2008-2009$ y $2009-2010$, respectivamente. Aquí cabe destacar que a diferencia de las otras categorías en las que la situación generalmente empeoraba a medida que se profundizaba en la crisis, en el caso de los autónomos los casos que encontramos fuera de muestra son decrecientes y, de cualquier forma, mucho menores que los que veíamos en las categorías indefinido, temporal o desempleado.

Pero la mejor manera de comprobar la dificultad para realizar transiciones la encontramos analizando plazos más largos que las comparaciones bianuales llevadas a cabo hasta ahora. Por eso, en la tabla 4 se pueden observar las trayectorias de cuatro años, los que transcurren entre 2007 y 2010.

Los porcentajes muestran ciertamente datos preocupantes. A saber, que menos de la mitad de los indefinidos de 2007 continúan en el mismo episodio cuatro años más tarde $(47,3 \%)$ y casi una tercera parte se encuentran fuera de muestra $\mathrm{y}$, por lo tanto, ni trabajan ni perciben prestaciones de desempleo; o que el panorama para los temporales es aún más sombrío, ya que solo el $2,9 \%$ ha conseguido transitar hasta un empleo indefinido mientras que el $27,4 \%$ ha terminado en el desempleo, o lo que es peor, casi la mitad ya no tiene derecho a recibir prestaciones y se encuentra fuera de la muestra (47,2\%). Estos datos irían en la línea de las conclusiones de Toharia (2005) para quien el problema de la temporalidad en España es que está muy arraigada y sus causas van más allá de los costes de despido o de la estacionalidad de muchos empleos.

Peor es la situación para aquellos que partían en situación de paro en 2007, cuyas transiciones hacia la estabilidad han resultado una quimera, pues casi la tercera parte atraviesa cuatro años después por otro episodio de desempleo $(29,9 \%)$, más de la mitad han agotado prestaciones y/o ya no buscan empleo (50,5\% fuera de muestra), e incluso un 7,0\% no ha conseguido salir del mismo episodio de desempleo en el que se encontraba en 2007. Y las transiciones hacia el empleo fueron prácticamente residuales: el $9,8 \%$ de quienes se encontraban sin trabajo en 2007 tiene un contrato temporal y un pírrico $2,8 \%$ ha conseguido en 2010 uno indefinido partiendo de la situación de paro de cuatro años antes.

Y de nuevo los autónomos se muestran como la categoría más estable, ya que el $66,2 \%$ se mantuvo en el mismo episodio que en 2007 , si bien casi una cuarta parte, el $24,8 \%$ se ha ido fuera de la muestra. Además, las transiciones hacia otro tipo de empleo son, como en las comparaciones entre dos años, residuales: el 1,3\% tiene un contrato indefinido partiendo del empleo por cuenta propia en 2007 y menos del $4,0 \%$ se encuentran trabajando de forma temporal o en el desempleo.

Por lo tanto, los datos recabados en este análisis de transiciones reflejan el alto grado de rotación del mercado laboral español pero también las dificultades existentes para realizar transiciones en y hacia el empleo de un importante contingente de trabajadores, 
confirmando la elevada flexibilidad externa pero también la inseguridad del mercado de trabajo que pronosticaba la hipótesis de partida planteada en este artículo.

Solamente los trabajadores que partían con un contrato indefinido consolidado parecen resistir mejor los embates de la crisis de empleo, mientras que los que fueron contratados en esa modalidad a partir de 2007 sufren la inestabilidad tanto como los temporales. Además, aun siendo difícil conseguir estabilidad entre las distintas categorías laborales, haberse quedado desempleado durante el período objeto de análisis es el peor de los escenarios posibles para conseguir futuras transiciones laborales, en tanto que los autónomos parecen mantenerse mejor en el mismo episodio de empleo, al menos en el corto plazo.

\section{Conclusiones}

El éxito de las medidas que en materia de flexiguridad plantean la Agenda de Lisboa y la Estrategia 2020 es incierto en el momento actual. Las distintas disposiciones educativas, laborales y económicas de los países de la Unión y la inseguridad que la crisis ha introducido en las agendas políticas impiden ver un horizonte claro en el camino de la flexiguridad. Sobre todo porque los actores implicados todavía no han tomado una decisión sobre qué políticas están dispuestos a aplicar y a qué coste, o cuáles pueden asumir de aquí en adelante las maltrechas economías europeas.

Así que la cuestión quizás no sea si la flexiguridad es un concepto útil sino si lo es en tiempos de crisis. La respuesta de este artículo es que, precisamente en los momentos de recesión económica, es en donde mejor se ven las carencias del sistema y más decisivo resulta el diseño de nuevas políticas. En las fases económicas expansivas no han existido en España suficientes incentivos para el cambio, y así ocurría en 2007, cuando se alcanzaron los niveles más bajos de desempleo de su historia reciente. Sin embargo, los elevados niveles de paro alcanzados durante la crisis y la rapidez con la que ha crecido el número de desempleados, demuestran que España sigue adoleciendo de los mismos problemas estructurales, como hemos podido comprobar en el presente trabajo. El mercado de trabajo español carece, por una parte, de la suficiente flexibilidad interna para adaptarse al nuevo escenario planteado por la actual crisis económica y de empleo. Igualmente, no puede obviarse la presencia de una elevada inseguridad, asociada principalmente a las tasas de desempleo, al paro de larga duración y a la dificultad para realizar transiciones laborales.

Se podría decir, por tanto, que la hipótesis de partida planteada es correcta, pues estas caracterización de flexibilidad externa y alta inseguridad sitúan al mercado de trabajo español en un escenario más próximo a la noción de "seguridad en el puesto de trabajo" que a la de "seguridad en el empleo". No obstante, no parece sencillo conciliar una política uniforme de flexiguridad. En primer lugar porque la elección de un térmi- 
no sintético como el de flexiguridad abre mucho el abanico de las posibles políticas a implementar y no permite delimitar con precisión hasta dónde llega la flexibilidad y en qué momento comienza la seguridad. En segundo lugar, porque las realidades sociales y económicas de los países que lideran las políticas de flexiguridad son muy distintas a las del resto, y con ello las rutas a seguir van a ser forzosamente desiguales. Así que existen notables diferencias con respecto al mercado de trabajo español que podrían hacer fracasar la transposición sin más de estos modelos.

En el presente artículo se ha encarado un concepto multidimensional como el de la flexiguridad, y las transiciones laborales son sólo una de las dimensiones analíticas de un concepto poliédrico y tangencialmente relacionado con muchas materias. Entre otras, conviene no perder de vista la negociación colectiva española. El éxito de las políticas de flexiguridad en Dinamarca se debe, en gran medida, a que los agentes sociales se encuentran presentes en todos los niveles de la negociación y existe una continua cooperación, lo que permite identificar mejor los territorios comunes y encontrar mecanismos de resolución de conflictos.

Al igual que en Dinamarca, en Holanda existe un alto nivel de confianza entre los agentes sociales y un sistema corporativo de relaciones laborales, pero la política socio-económica ha sido distinta a la danesa. En el país nórdico el gobierno otorga una amplia discrecionalidad a los interlocutores para el diseño de las políticas sociales, mientras que en el caso holandés, el gobierno es más activo en la toma de decisiones. Austria, por su parte, combina la presencia del "partenariado social" con una relativamente elevada flexibilidad del mercado laboral, un buen nivel de prestaciones sociales y un eficaz modelo de activación e indemnizaciones por despido.

Por tanto, también habría que considerar, cuál de los itinerarios de la flexiguridad adoptados se podría adaptar mejor a la realidad del caso español. Austria constituye un buen ejemplo de seguridad tanto en el trabajo como en el empleo, Holanda representa el paradigma de la flexibilidad - especialmente interna - en Europa, mientras que Dinamarca mantiene un buen equilibrio entre ambas dimensiones. Así que, teniendo en cuenta que la segmentación por tipo de contrato y las medidas flexibilizadoras se ha convertido características distintivas del mercado laboral español (ver apartado 2), parece más fácilmente replicable una flexiguridad "a la holandesa". Holanda eligió una ruta diferente para incrementar la flexibilidad del mercado laboral, en la que los esfuerzos se han concentrado en el trabajo a tiempo parcial. Pero el principio de igualdad en el trato otorgado a los trabajadores temporales y la mejora sustancial de su nivel de protección también ha reforzado la posición de los trabajadores, otorgándoles seguridad. Todo ello aleja a la temporalidad holandesa de los estándares habituales de inestabilidad e inseguridad. 


\section{Bibliografía}

Andersen, T. y M. Svarer (2007): "Flexicurity-Labour Market Performance in Denmark", CESIfo Economic Studies, 53 (3). Dispinible en:

$<$ http://dx.doi.org/10.1093/cesifo/ifm015> [Último acceso, 15 de Julio de 2015].

BBVA Research (2011): “Desempleo juvenil en España: causas y soluciones”, Servicio de Estudios del BBVA, Documentos de Trabajo número 11/30, Madrid.

Burroni, L. y M. Keune (2011): "Flexicurity: A conceptual critique”, European Journal of Industrial Relations, 17 (1), pp. 75-91.

Comisión de las Comunidades EuRopeas (2007): "Hacia los principios comunes de la flexiguridad: más y mejor empleo mediante la flexibilidad y la seguridad", Comunicación de la Comisión al Parlamento Europeo, al Consejo, al Comité Económico y Social Europeo y al Comité de las Regiones, Bruselas, 27.6.2007 COM (2007): 359-final. Disponible en:

$<$ http://eur-lex.europa.eu/LexUriServ/LexUriServ.do?uri=COM:2007:0359:FIN:ES:PDF> [Último acceso 15 de Julio de 2014].

De Gier, E. y A. Van den Berg (2006): "Gestión de los riesgos sociales por medio de los mercados de trabajo transicionales: hacia una estrategia europea de empleo enriquecida", en Luis Toharia (comp.), Los mercados de trabajo transicionales: nuevos enfoques y políticas sobre los mercados de trabajo europeos, Madrid, Ministerio de Trabajo e Inmigración, 29: pp. 353-457.

Doeringer, P. y M. Piore (1985): Mercados internos de trabajo y análisis laboral, Madrid, Ministerio de Trabajo y Seguridad Social.

European Commission (2009): Employment in Europe 2009. Directorate General for Employment, Social Affairs and Equal Opportunities. Luxembourg: Office for Official Publications of the European Communities.

European Communities (2001): "Council Recommendation of 15 June 2001 on the broad guidelines of the Economic Policies of the Member States and the Community". Official Journal (2001/483/EC). Disponible en:

$<$ http://eur-lex.europa.eu/legal-content/EN/TXT/PDF/?uri=CELEX:32001H0483\&from=EN> [Último acceso 31 de marzo de 2015].

EUROSTAT, Statistics by theme. Disponible en:

$<$ http://epp.eurostat.ec.europa.eu/portal/page/portal/statistics/themes $>$ [Último acceso 15 de Julio de 2014].

GuillÉN, A. M. y R. GuTiÉRRez (2008): "Treinta años de pactos sociales en España: un balance". Cuadernos de Información económica, 203, pp. 173-180.

Instituto Nacional de Estadística, Directorio central de empresas (DIRCE). Disponible en:

$<$ http://www.ine.es/jaxiBD/menu.do?type $=$ db \&divi $=$ dir\&his $=0 \& \mathrm{~L}=0>$ [Último acceso 15 de Julio de 2014]. 
Instituto Nacional de Estadística, Movimiento laboral registrado. Disponible en: $<$ http://www.ine.es/jaxi/menu.do?type $=$ pcaxis\&path $=/ \mathrm{t} 22 / \mathrm{a} 061 \&$ file $=$ inebase $\& \mathrm{~L}=0>$ Último acceso 15 de Julio de 2014].

Jepsen, M. y A. Serrano (2006): Unwrapping the European Social Model, Bristol, Policy Press.

Keune, M. y M. JePSEn (2007): "Not balanced and hardly new: the European Commision's quest for flexicurity", en Jørgensen, H. y P. Kongshøj Madsen (eds.), Flexicurity and Beyond, Copenhagen, DJØF Publishing.

KöHLer, H.-D. y A. Martín-Artiles (2005): Manual de la Sociología del Trabajo y de las Relaciones Laborales, Madrid, Delta Publicaciones.

Koster, F., J. Mcquinn, I. Siedschlag y O. Van Vliet (2011): "Labour Market Models in the UE”, NEUJOBS Special Report, 1, Leiden University/ESRI, 23. Disponible en: $<$ http://dare.uva.nl/document/448479> [Último acceso 15 de Julio de 2014].

MADSEN, K. (2004): "The Danish model of 'flexicurity'. Experiences and lessons", Transfer: European Review of Labour and Research, 10 (2), pp. 187-207. Disponible en: doi:10.1177/102425890401000208. [Último acceso, 29 de Marzo de 2015]

Mato, J. y B. Cueto (2008): "Efectos de las políticas de formación a desempleados", Revista de Economía Aplicada, 46, pp. 61-84.

Polavieja, J.G. (2003): Estables y Precarios: Desregulación Laboral y Estratificación Social en España, Madrid, Centro de Investigaciones Sociológicas.

Ruesga, S. (dir.) (2011): Hacia un nuevo modelo de financiación de la Seguridad Social en España, Premio Programa FIPROS 2011- Madrid, Ministerio de Empleo y Seguridad Social.

Schmid, G. y K. Schömann (2006): "El concepto de mercados de trabajo transicionales y algunas conclusiones para la política de empleo: el estado de la cuestión", en Luis Toharia (comp.), Los mercados de trabajo transicionales: nuevos enfoques y políticas sobre los mercados de trabajo europeos, Madrid, Ministerio de Trabajo e Inmigración, 29 , pp. 15-40.

Serrano Pascual, A. (2007): "Reshaping Welfare States: Activation Regimes in Europe", en Serrano Pascual, A. y L. Magnusson (eds.), Reshaping welfare states and activation regimes in Europe, Bruselas, P.I.E.-Peter Lang, pp. 11-35.

(2009): "Regulación supranacional y despolitización del trabajo: el caso del paradigma de la activación", en E. Crespo, C. Prieto y A. Serrano (dirs.), Trabajo, subjetividad y ciudadanía. Paradojas del empleo en una sociedad en transformación, Madrid, Editorial Complutense / CIS.

Serrano, A., Alba Artiaga, C. Fernández, P. Martín y J.F. Tovar (2009): Protección y flexiguridad: la modernización de los servicios públicos de empleo, Investigación Proyecto FIPROS 2008/35, Madrid, Ministerio de Trabajo e Inmigración. 
Tangian, A. (2007): "Flexibility-Flexicurity-Flexinsurance: Response to the European Commission's Green Paper "Modernising Labour Law to Meet the Challenges of the 21st Century", WSI-Diskussionpapier no. 149, Wirtschafts - und Sozialwissenschaftliches Institut in der Hans Böckler Stiftung. (2008): "On the European Readiness for Flexicurity: Empirical Evidence with OECD/ HBS Methodologies and Reform Proposals", Wirtschafts - und Sozialwissenschaftliches Institut in der Hans Böckler Stiftung, WSI-Diskussionpapier no. 160.

(2009): "Six families of flexicurity indicators developed at the Hans Böeckler Foundation", Wirtschafts - und Sozialwissenschaftliches Institut in der Hans Böckler Stiftung, WSI-Diskussionpapier no. 168.

- (2010): "Not for bad weather. Macroeconomic analysis of flexicurity with regard to the crisis, Brussels, ETUI working paper.

TOHARIA, L. (dir.) (2005): El problema de la temporalidad en España: un diagnóstico, Madrid, MTAS, Colección Economía y Sociología del Trabajo.

TOHARIA, L. e I. CEBRIÁN (2007): La temporalidad en el empleo: atrapamiento y trayectorias, Madrid, MTAS, Colección Informes y Estudios, $\mathrm{n}^{\circ} 32$.

Tovar, F.J. y J. C. Revilla (2012): La institucionalización de la individualización del trabajo: el concepto de flexiguridad, Cuadernos de Relaciones Laborales, 30 (1), pp. 235-258.

Unión Europea (2007): Síntesis de la legislación de la UE. Disponible en: $<$ http://europa.eu/legislation_summaries/employment_and_social_policy/community_ employment_policies/c11335_es.htm> [Último acceso 15 de Julio de 2014].

Valdés Dal Ré, F. (2004): “The difficulty of reconciling flexibility and security in Spain: the paradigmatic case of part-time work", Transfer: European Review of Labour and Research, 10 (2), pp. 248-262. Disponible en:

doi:10.1177/102425890401000208 [Último acceso, 23 de Marzo de 2015].

VAldÉs Dal-Ré, F. y J. LAhera (2010): "La flexiguridad laboral en España", Madrid, Fundación Alternativas, Documento de trabajo 157/2010.

Wilthagen, T. y F. Tros (2004): "The concept of 'flexicurity': a new approach to regulating employment and labour markets", Transfer, 10 (2), pp. 166-186. Disponible en:

$<$ http://dx.doi.org/10.1177/102425890401000204> [Último acceso, 15 de Julio de 2015]. 